University of Nebraska - Lincoln

DigitalCommons@University of Nebraska - Lincoln

6-7-1998

\title{
Characterization of protective immune responses in local lymphoid tissues after drug-attenuated infections with Ostertagia ostertagi in calves
}

S. AlmerÂõa

A. Canals

M.T. Gomez- Munos

D.S. Zarlenga

L.C. Gasbarre

Follow this and additional works at: https://digitalcommons.unl.edu/usdaarsfacpub

This Article is brought to you for free and open access by the U.S. Department of Agriculture: Agricultural Research Service, Lincoln, Nebraska at DigitalCommons@University of Nebraska - Lincoln. It has been accepted for inclusion in Publications from USDA-ARS / UNL Faculty by an authorized administrator of DigitalCommons@University of Nebraska - Lincoln. 


\title{
Characterization of protective immune responses in local lymphoid tissues after drug-attenuated infections with Ostertagia ostertagi in calves
}

\author{
S. Almería, A. Canals, M.T. Gómez-Muñoz, \\ D.S. Zarlenga, L.C. Gasbarre*
}

USDA, ARS, LPSI, Immunology and Disease Resistance Laboratory, Beltsville, MD 20705, USA

Received 3 November 1997; accepted 7 June 1998

\begin{abstract}
In the present study, cell-surface markers and cytokine gene expression of lymphocytes from the local lymph nodes were studied 9 days after primary infection with Ostertagia ostertagi in previously naive calves or in calves previously immunized with multiple, chemically attenuated infections. Changes in lymphocyte populations were assessed by flow cytometry utilizing monoclonal antibodies specific for bovine cell-surface markers. Changes observed in the percentages of lymphoid populations after challenge were similar in animals immunized by either three or five drug-attenuated infections. In both immunized groups, the $\mathrm{CD} 4^{+} / \mathrm{CD} 8^{+}$ratio was significantly higher than in naive animals after challenge infections. In addition, both immunized groups showed significantly lower levels of Ig-bearing cells upon experimental challenge when compared to animals with a primary experimental infection. No differences were observed in the number of $\gamma \delta$ or interleukin 2 receptor (IL-2R) positive cells. The levels of mRNA for IL-4, IL-10, IL-15, IFN- $\gamma$ and TGF- $\beta 1$ were examined by competitive RT-PCR. After challenge, the levels of these cytokines were lower in animals immunized by five drug-attenuated infections, and in the case of IL- 4 and TGF- $\beta 1$, these differences were statistically significant. These results indicate that animals exhibiting protection from reinfection with $O$. ostertagi do not show a shift to higher percentages of $\mathrm{Ig}^{+}$cells characteristic of a primary infection. In addition, protected animals appear to show a decreased IL4 and TGF- $\beta 1$ response upon challenge when compared to non-immune animals. Published by Elsevier Science B.V.
\end{abstract}

Keywords: Ostertagia ostertagi; Immunity; Cattle; Cytokines

* Corresponding author. Tel.: +1 301504 8509; fax: +1 3015045306.

0304-4017/98/\$ - see front matter Published by Elsevier Science B.V.

PII: S 0304 - 4017 (98) 00185 - X

U.S. government works are not subject to copyright. 


\section{Introduction}

Gastrointestinal (GI) nematodes constitute an important constraint on the productivity of ruminants, with Ostertagia ostertagi being the most economically important GI nematode in cattle in temperate regions. Control of GI nematodes has been largely based on repeated administration of anthelminthics (Williams, 1997) and there are increasing concerns about problems as drug residues or the development of anthelmintic resistance in systems that remain completely dependent on drug usage (Waller, 1997). An elucidation of the mechanisms that contribute to protective immunity in ruminants against nematode parasites would assist in the development of alternative control strategies to those presently used.

In earlier studies characterizing the immune responses against $O$. ostertagi, it was observed that a primary infection induces changes in surface marker staining in regional lymphocyte populations. These changes in the abomasal lymph nodes (ABLN) include a decrease in the percentage of T cells (Gasbarre, 1994) and elevated percentages of Bcells, $\gamma \delta$-T cells and cells expressing the IL-2 receptor (IL-2R) (Almería et al., 1997a). These changes indicated that the first two weeks of infection was a critical time for expansion and regulation of cell populations in $O$. ostertagi infected calves. This time interval coincides with larval development (Gasbarre, 1994). In spite of the profound changes occurring early in primary infections, these responses are not associated with protective immunity. Moreover, prolonged exposure to repeated oral inoculations is required to induce even partial protection (Michel et al., 1973). When subjected to prolonged exposure, immunized animals are able to maintain normal T-cell percentages and the normal ratios of T-cell subpopulations in the draining lymph nodes (Gasbarre, 1994).

Cytokines, particularly, those secreted by $\mathrm{CD}^{+}{ }^{+}$T-helper cells (Th) are critical for the regulation of the immune responses against parasites (Grencis, 1996). Certain CD4 ${ }^{+} \mathrm{T}-$ cell clones can be subdivided into subsets according to distinct patterns of cytokine production: T helper 1 (Th1) lymphocytes produce most notably IFN- $\gamma$ and IL-2, whereas T helper 2 (Th2) lymphocytes produce IL-4, IL-5 and IL-10 among others. In cattle, studies focusing on IL-2, IL-4, IL-10 and IFN- $\gamma$, cytokine mRNA profiles induced by a primary $O$. ostertagi infection showed a less restricted Th1/Th2 profile than that observed in murine models in both the draining lymph nodes (Canals et al., 1997) and in lymphocytes isolated from the mucosa (Almería et al., 1997b). In these studies IL-4, IL10 and IFN- $\gamma$ mRNA levels were increased after a primary infection. As indicated previously, these changes were not related to protective immunity in the animals, raising questions concerning the importance of these early responses in the acquisition of protective immunity against reinfection and of the role of the different lymphocyte subpopulations in protective immunity.

Parasitic infection is frequently accompanied with a downregulation in host cellmediated immunity (Sher et al., 1992). This modulation can, at least, be attributed to the action of inhibitory cytokines, the most characteristic being IL-4, IL-10 and TGF- $\beta$ (Sher et al., 1992). TGF- $\beta$ is a multifunctional cytokine that appears to be involved in many processes of tissue development and repair, including inflammation and tumorigenesis (Massague, 1990). It also functions as a potent growth inhibitor (Tucker et al., 1984). In 
parasitic infections, TGF- $\beta$ has been described as a parasite escape mechanism for Leishmania (Barral-Netto et al., 1992) and a TGF- $\beta$ homolog has been related to the promotion of non-dauer development of Caenorhabditis elegans (Ren et al., 1996).

In this study, phenotypic changes and cytokine gene expression in the local lymph nodes were examined in cattle subjected to infections attenuated by anthelmintic treatment 9 days after infection (L4 stage). This protocol has been shown to provide a degree of protective immunity against O. ostertagi (Gasbarre, 1988). The resulting responses were compared to the immune response after a single non-protective infection with $O$. ostertagi. The study included, for the first time, cytokine analysis of relative quantities of bovine TGF- $\beta 1$ in an $O$. ostertagi infection.

\section{Materials and methods}

\subsection{Immunization protocol}

Calves were acquired at one day of age and kept housed indoors in concrete-floored pens throughout the experiment to preclude extraneous parasite exposure. The experimental design consisted of two blocks of eight animals each. Within blocks, animals were allocated to treatments groups according to body weight. In the first block, Group Im-1 (4 calves) received three drug-attenuated immunizing infections prior to receiving an experimental challenge inoculum while group PInf-1 (4 calves) received only the challenge inoculum. In the second block, group Im-2 (4 calves) received five drug-attenuated immunizing infections prior to receiving an experimental challenge inoculum with group PInf-2 (4 calves) receiving only the challenge inoculum.

Immunization consisted of infection with $2 \times 10^{5}$ infective larvae (L3) of $O$. ostertagi at day 0 . Nine days after the infection, the animals were treated with $10 \mathrm{mg} / \mathrm{kg}$ of fenbendazole and after a rest period of $\approx 27$ days, infections were repeated to give a total of three (Im-1) or five (Im-2) attenuated infections. Control animals (PInf-1 and PInf-2) received only the anthelmintic treatments. Animals were challenged with $1 \times 10^{5} \mathrm{~L} 3$ of $O$. ostertagi 27 days after the final drug treatment in each block, and killed 10 days later.

In order to study TGF- $\beta 1$ mRNA levels, three age-matched parasite-free calves were added for comparison to a primary infection (PInf-2 group) and to animals immunized by five drug-attenuated infections (Im-2 group).

\subsection{Parasite burdens}

The abomasa were isolated, opened longitudinally and the contents collected by washing with warm water. An aliquot consisting of $20 \%$ of the wash was taken and fixed with formalin. A $10 \%$ aliquot of this sample was examined for parasites. After washing, the abomasa were incubated in saline, at room temperature for $24 \mathrm{~h}$. At the end of the 24$\mathrm{h}$ incubation period, the surface of the abomasum was rubbed and the subsequent suspension fixed with formalin. A total of $10 \%$ of the suspension was examined for parasites. Parasite examination involved enumeration of parasites, and classification of adults and developing worms. 


\subsection{Isolation of abomasal lymph node cells $(A B L N)$.}

Abomasal lymph nodes were collected aseptically at slaughter, and the isolation of ABLN cells was performed as previously described (Gasbarre, 1994). Briefly, cell suspensions were obtained by teasing apart the nodes, and debris was removed by gravity sedimentation. Cells were washed with calcium-magnesium free Hanks' balanced salt solution (HBSS) and stored on ice until RNA extraction.

\subsection{Immunofluorescence staining}

Immunofluorescence staining was performed as described by Gasbarre (1994). The monoclonal antibodies (mAb) used in this study and their specificities for bovine leukocyte surface antigens are described in Pasquali et al. (1997). The mAb PT85 which recognizes a monomorphic determinant on class I antigens, was used as a positive control. Control mouse ascites fluid was used for the determination of background staining levels. Flow cytometry was performed with an Epics profile II flow cytometer (Coulter, Hialeah, FL).

\subsection{RNA isolation}

Isolated cells were lysed in guanidinium isothiocyanate buffer (4M Guanidinium Isothiocyanate, $5 \mathrm{mM} \mathrm{Na}$ Citrate, $10 \mathrm{mM}$ EDTA, 0.5\% Na Sarkosyl, $100 \mathrm{mM} 2-$ mercaptoethanol) and kept at $-80^{\circ} \mathrm{C}$. Total RNA was extracted according to the method of Chomczynski and Sacchi (1987). Samples were treated with DNAse (2.5 U DNAse RNase free) in the presence of RNAse inhibitors (80 U RNAse inhibitor) for $5 \mathrm{~min}$ at $37^{\circ} \mathrm{C}$ to eliminate contaminating genomic DNA. Concentrations of RNA were determined spectrophotometrically, and integrity was checked by denaturing agarose gel electrophoresis.

\subsection{Competitive RT-PCR}

Synthesis of cDNA was performed in a total volume of 40 ul using 10 ug of total RNA in the presence of oligo dT and reverse transcriptase (superscript preamplification system (GibcoBRL, Gaithersburg, MD) following the manufacturer's recommendations.

The competitor molecule for bovine TGF- $\beta 1$ was constructed as previously described (Zarlenga et al., 1995). The size of the amplified products and the primer sequences for bovine IL2, IL4, IL-10, IFN- $\gamma$ and TGF- $\beta 1$ are listed in Table 1. The single concentration of competitor used in each experiment was determined empirically, using serial dilutions (data not shown) so that intensities from competitor and cDNA fragments could be quantified. One constant concentration was then used for each experiment. Competitor concentrations were: $100 \mathrm{fg}$ for IL-10; $0.5 \mathrm{fg}$ for IL-15, $7 \mathrm{fg}$ for IFN- $\gamma, 0.4 \mathrm{fg}$ for IL4, and 220 fg for TGF- $\beta 1$.

Conditions for the polymerase chain reaction (PCR) were described in detail in Canals et al. (1997). PCR amplification was performed in a Perkin-Elmer (Perkin-Elmer, 
Table 1

Cytokine competitors, size (bp) of the fragment amplified from cDNA and competitor, and forward and reverse primer sequences used in the competitive RT-PCR

\begin{tabular}{|c|c|c|c|}
\hline \multirow{2}{*}{$\begin{array}{l}\text { Cytokine } \\
\text { competitor }\end{array}$} & \multicolumn{2}{|c|}{ Size (bp) } & \multirow[t]{2}{*}{ Primer } \\
\hline & cDNA & competitor & \\
\hline IL-15 & 468 & 384 & $\begin{array}{l}\text { CATATTTGAGAAGTACTTCCATCCAG (F) } \\
\text { GAAGTGTTGATGAACATTTGCAC (R) }\end{array}$ \\
\hline IL-4 & 400 & 310 & $\begin{array}{l}\text { ATGGGTCTCACCTACCAGCTG (F) } \\
\text { CAACACTTGGAGTATTTCTCCT (R) }\end{array}$ \\
\hline IL-10 & 590 & 465 & $\begin{array}{l}\text { ATGCATAGCTCAGCACTACTCTGTTGCCTG (F) } \\
\text { TCACTTTTGCATCTTCGTTGTCATGTAGGTT (R) }\end{array}$ \\
\hline IFN- $\gamma$ & 440 & 310 & $\begin{array}{l}\text { TATGGCCAGGGCCAATTTTTTAGAGAAATA (F) } \\
\text { TTACGTTGATGCTCTCCGGCCTCGAAAGAG (R) }\end{array}$ \\
\hline TGF- $\beta$ & 608 & 455 & $\begin{array}{l}\text { AGAAGATCTCTGCTGTGTTCGTCAGCTCTAC (F) } \\
\text { CGGAGATCTGAACTGAACCCGTTAATGTCC (R) }\end{array}$ \\
\hline HPRT & 230 & 186 & $\begin{array}{l}\text { GGAGATGATCTCTCAACTTTAACTGG }(\mathrm{F}) \\
\text { CATTATAGTCAAGGGCATATCCCAC }(\mathrm{R})\end{array}$ \\
\hline
\end{tabular}

Norwalk, CT) DNA thermal cycler (Gene Amp 9600). Cytokine quantification was done after 35 cycles of $94^{\circ} \mathrm{C}$ for 30 -s denaturation, $55^{\circ} \mathrm{C}$ for 1 -min annealing, and $72^{\circ} \mathrm{C}$ for 2-min polymeration. Amplification of hypoxanthine phosphoribosyltransferase (HPRT) and the corresponding competitor molecule served as a positive control for cDNA synthesis and was normalized to a cDNA/competitor ratio of one prior to the amplification of the cytokines. The cDNA and competitor products from each tube were distinguished by size separation in a $1.8 \%$ Metaphore : $0.2 \%$ GTG agarose gel and were visualized by staining with ethidium bromide. The relative amounts of each cytokine and competitor were quantified by scanning photographed gels, using Sigmagel (Jandel Scientific, San Rafael, CA). Scanned results were expressed as relative intensities $(R)$ of the target cDNA band $(A)$ to competitor band $(B)(R=A / B)$ and normalized to the amount of HPRT in each sample. Ratios are relative intensity values and do not necessarily reflect fold differences in the amount of cytokine mRNA produced between two analyzed samples.

\subsection{Statistical analysis}

Differences between previously naive and immunized groups were tested by the $t$-Test. When normality test or homogenicity of variance failed, differences were tested by the non-parametric Mann-Whitney rank sum test. For TGF- $\beta 1$, differences among the three groups were tested by a one-way analysis of variance (ANOVA). When assumptions of normality or homogenicity of variance failed, the non-parametric Kruskal-Wallis oneway ANOVA on ranks was performed. Values were considered statistically different when $p<0.05$. Correlation coefficients between cytokine ratios and percentages of stained cells were calculated by Pearson product moment correlation. 
Table 2

Worm burdens in primed animals and in Ostertagia ostertagi immunized animals *

\begin{tabular}{llll}
\hline Group & Developing worms & Adult worms & Total worms \\
\hline PInf-1 & $19.6 \pm 8.8^{\mathrm{a}}$ & $0.0 \pm 0.0^{\mathrm{a}}$ & $19.6 \pm 8.8^{\mathrm{a}}$ \\
Im-1 & $11.1 \pm 3.1^{\mathrm{a}}$ & $0.1 \pm 0.1^{\mathrm{a}}$ & $11.2 \pm 3.2^{\mathrm{a}}$ \\
\hline PInf-2 & $15.2 \pm 1.8^{\mathrm{a}}$ & $0.0 \pm 0.0^{\mathrm{a}}$ & $15.2 \pm 1.8^{\mathrm{a}}$ \\
Im-2 & $4.1 \pm 3.9^{\mathrm{b}}$ & $0.0 \pm 0.0^{\mathrm{a}}$ & $4.1 \pm 3.9^{\mathrm{b}}$ \\
\hline
\end{tabular}

* Data represent the mean of four animals sacrificed per date \pm S.D. Data expressed as worm number $\times 10^{3}$. Different letters within a block indicate statistically significant differences $(p<0.05)$.

\section{Results}

\subsection{Worm counts}

The numbers of worms recovered from the animals are presented in Table 2. After three drug-attenuated infections, the immunized group Im-1 showed a $43 \%$ reduction in mean worm burdens (11200 worms) compared to the primary infected group, PInf-1 $(19,600$ worms). However, this difference was not statistically significant $(p=0.12)$, (Table 2). After five drug-attenuated infections, group Im-2 exhibited a 73.2\% reduction of mean worm counts (4100) compared to the primary infected group PInf-2 (15 200) $(p=0.03)$.

\subsection{Surface marker phenotypes}

More than $50 \%$ of the cells recovered were $\mathrm{CD}^{+}$, and the predominant $\mathrm{T}$ subset in all groups was $\mathrm{CD}^{+}$(Table 3). Levels of $\mathrm{CD}^{+}$cells were slightly increased in the immunized groups, although differences were not statistically significant, and percentages of $\mathrm{CD}^{+}$cells were significantly reduced in animals after either three or five drug-attenuated infections when compared with their respective primary infected group ( $p=0.01$ and 0.05 , respectively) (Table 3 ). The $\mathrm{CD} 4^{+} / \mathrm{CD}^{+}$ratios were lower in the primary infected groups when compared to the ratios in the immunized groups ( $2.2 \pm 0.2$ vs. $3.2 \pm 0.4, p=0.03$ in PInf1 and Im-1, respectively) and $1.9 \pm 0.4$ vs. $3.0 \pm 0.2$, $p=0.002$ in PInf-2 and Im-2, respectively).

Table 3

Cell-surface phenotypes of abomasal lymph node cells (ABLN) in primed animals and in Ostertagia ostertagi immunized animals. Results expressed as mean of four individual animals \pm S.D.*

\begin{tabular}{llllllll}
\hline Cell source & Group & CD3 & CD4 & CD8 & WC1 & IL2R & IgM \\
\hline ABLN & PInf-1 & $59.4 \pm 5.1^{\mathrm{a}}$ & $42.2 \pm 5.1^{\mathrm{a}}$ & $19.5 \pm 1.2^{\mathrm{a}}$ & $31.8 \pm 2.5^{\mathrm{a}}$ & $24.4 \pm 2.2^{\mathrm{a}}$ & $56.3 \pm 4.1^{\mathrm{a}}$ \\
& Im-1 & $62.7 \pm 8.6^{\mathrm{a}}$ & $48.2 \pm 3.7^{\mathrm{a}}$ & $15.2 \pm 1.8^{\mathrm{b}}$ & $33.8 \pm 2.4^{\mathrm{a}}$ & $27.9 \pm 2.8^{\mathrm{a}}$ & $46.1 \pm 4.2^{\mathrm{b}}$ \\
\hline ABLN & PInf-2 & $51.2 \pm 7.8^{\mathrm{a}}$ & $36.8 \pm 5.4^{\mathrm{a}}$ & $19.0 \pm 2.7^{\mathrm{a}}$ & $25.8 \pm 3.4^{\mathrm{a}}$ & $26.7 \pm 1.3^{\mathrm{a}}$ & $45.7 \pm 6.3^{\mathrm{a}}$ \\
& Im-2 & $54.9 \pm 9.9^{\mathrm{a}}$ & $40.0 \pm 4.9^{\mathrm{a}}$ & $13.3 \pm 2.5^{\mathrm{b}}$ & $29.6 \pm 4.2^{\mathrm{a}}$ & $25.4 \pm 1.7^{\mathrm{a}}$ & $32.7 \pm 7.0^{\mathrm{b}}$ \\
\hline
\end{tabular}

* Different letters within a block indicate statistically significant differences $(p<0.05)$. 
The percentage of $\mathrm{B}$ cells ( $\operatorname{IgM}^{+}$cells) decreased in both immunized groups (Im-1 and Im-2) compared to their respective primary infected groups (Table 3) ( $p=0.014$ and 0.013 , respectively). In addition, animals immunized with five drug-attenuated infections had lower worm burdens and showed the lowest percentage of $\operatorname{IgM}^{+}$cells $(r=0.73$, $p=0.04)$. No differences were observed in the percentage of $\gamma \delta$ cells ( $\mathrm{WC}^{+}{ }^{+}$cells) and in the percentage of activated cells (IL2 $\mathrm{R}^{+}$cells) between immunized and primary infected animals in either immunization protocol.

\subsection{Cytokine mRNA gene expression}

All groups showed measurable levels of IL-4, IL-10, IL-15, IFN- $\gamma$ and TGF- $\beta 1$ transcrips (Figs. 1-3). No statistically significant differences were detected in animals immunized with three drug-attenuated infections compared to primary infected animals, although a decrease in IL-4 was observed in the immunized (Im-1) group compared to all but one of the animals in the primary infected (PInf-1) group $(p=0.32)$ (Fig. 1). Average

$I L-15$

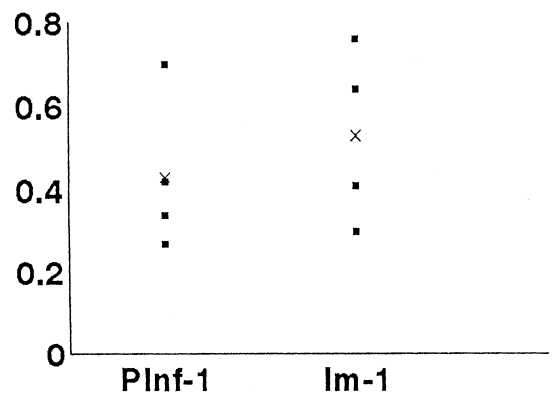

IFN-gamma

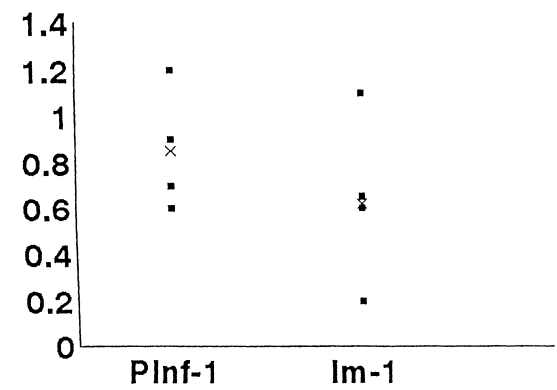

IL-10

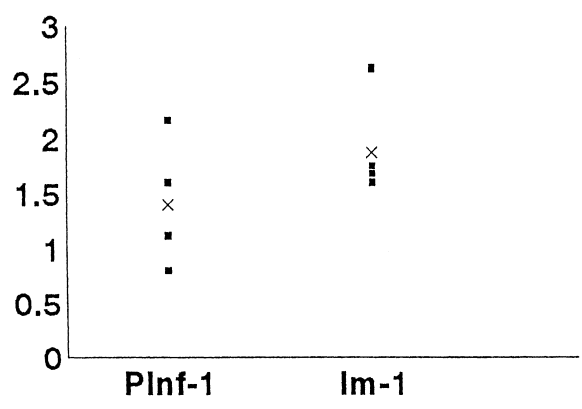

$I L-4$

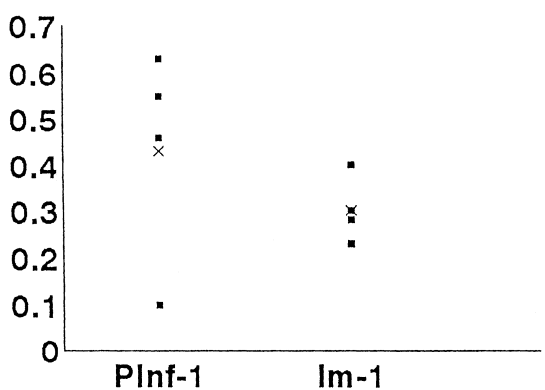

Fig. 1. Cytokine mRNA analysis of ABLN cells in animals after primary infection (PInf-1) and after three drugattenuated infections (Im-1) with $O$. ostertagi. Results are expressed as fluorescence intensity ratios of amplified native cDNA to competitor, and normalized to the HPRT values. ( $\square)$ Individual values and $(\times)$ group means are indicated. 
IL -15

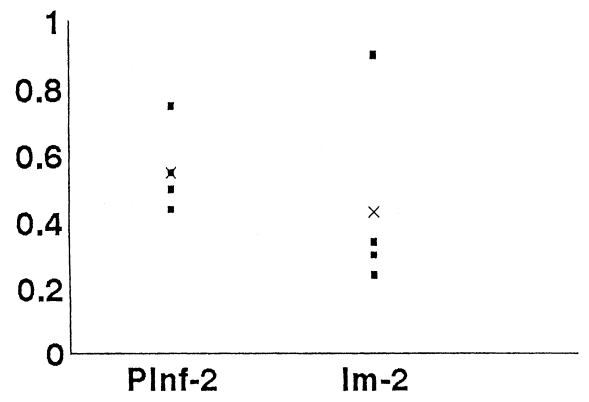

IFN-gamma

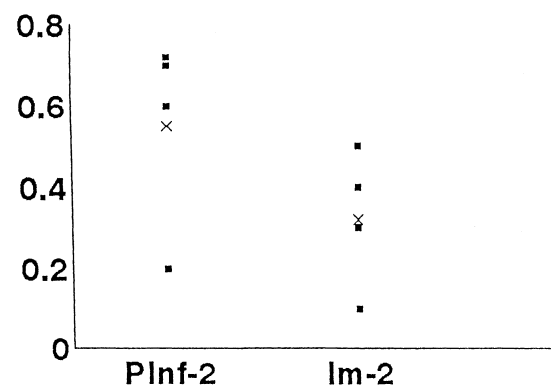

IL-10

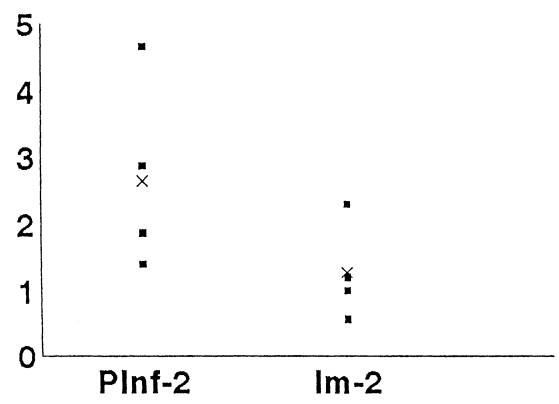

$I L-4$

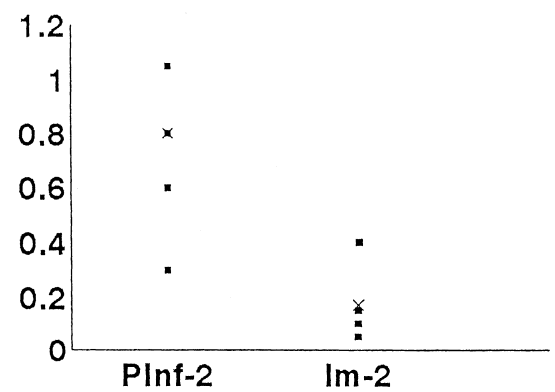

Fig. 2. Cytokine mRNA analysis of ABLN cells in animals after primary infection (PInf-2) and after five drugattenuated infections ( $\mathrm{Im}-2)$ with $O$. ostertagi. Results are expressed as fluorescence intensity ratios of amplified native cDNA to competitor, and normalized to the HPRT values. (ם) Individual values and $(\times)$ group means are indicated.

levels of IL-15 and IL-10 in the Im-1 group were slightly higher than those found in the PInf-1 group, while IFN- $\gamma$ levels were slightly lower in Im-1 compared to PInf-1 (Fig. 1).

After five drug-attenuated infections, there was a significant decrease $(p=0.027)$ in the level of IL-4 (Fig. 2) and the ratios of IL-4 ( $\left.\mathrm{R}_{4}\right)$ correlated with the number of worms $(r=0.79, p=0.02)$. Levels of IL-15, IL-10 and IFN- $\gamma$ decreased in the Im-2 group compared with the primary infected group (PInf-2) (Fig. 2), although these differences were not statistically significant ( $p>0.1,0.139$ and 0.175 , respectively).

Levels of TGF- $\beta 1$ were elevated $(p<0.05)$ in calves with a primary infection (PInf-2) when compared to both uninfected and immunized calves (Im-2) which showed similar levels of gene transcription (Fig. 3).

\section{Discussion}

The present study provides the first definition of cytokine responses of cells taken from animals exhibiting protective immunity to Ostertagi ostertagi. Protection from 


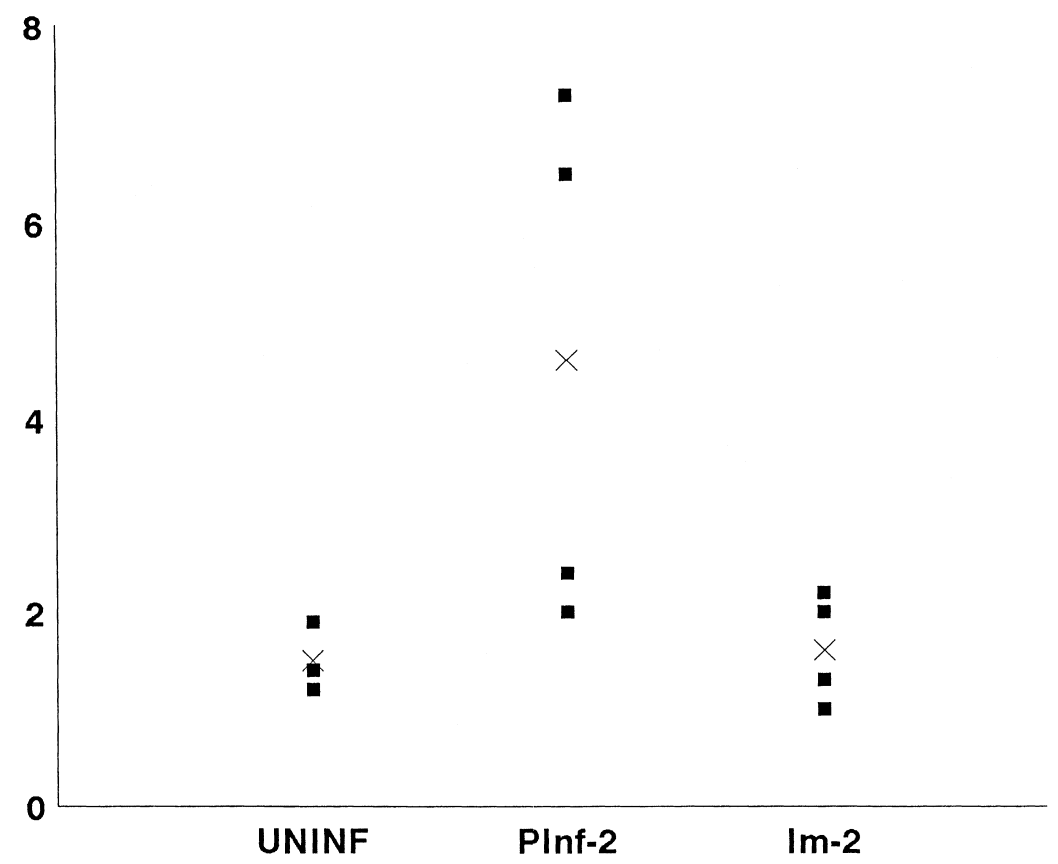

Fig. 3. Cytokine mRNA analysis of TGF- $\beta 1$ in ABLN cells in uninfected animals (UNINF), in animals after primary infection (PInf-2) and after five drug-attenuated infections (Im-2) with O. ostertagi. Results are expressed as fluorescence intensity ratios of amplified native cDNA to competitor, and normalized to the HPRT values. ( $\square)$ Individual values and $(\times)$ group means are indicated.

reinfection by $O$. ostertagi arises very slowly; is not absolute and requires prolonged host-parasite interaction (Michel et al., 1973; Armour, 1989; Gasbarre, 1986; Claerebout et al., 1996). In the present experiment, an immunization protocol of three drugattenuated infections provided partial immunity against experimental challenge and, only after five drug-attenuated infections with $O$. ostertagi was the number of parasites established after challenge significantly reduced. Our results are in agreement with a previous study (Gasbarre, 1988), supporting the idea that the protective immune response is induced by the death of the larvae in the abomasal glands. In contrast, Claerebout et al. (1996), in a study using trickle infections, truncated at either the L3 or L4 stage over 21 weeks, did not observe significant protective immunity, and indicated that infections truncated by anthelmintic treatment elicited poor development of immunity; however, the immunization protocol used in that study was different.

The differences in surface staining seen in ABLN populations of calves after a primary infection with $O$. ostertagi, are in agreement with previous studies (Gasbarre, 1994: Almería et al., 1997a, b). In these previous studies, the primary infected groups, when compared to control uninfected animals, showed increased levels of Ig-bearing cells, $\gamma \delta \mathrm{T}$ and activated cells, and lower percentages of $\mathrm{T}$ cells, mainly due to a reduction in the $\mathrm{CD}^{+}$subset, as observed by Gasbarre (1994). In naturally infected steers, increased 
percentages of B-lymphocytes, related to the number of O. ostertagi and Cooperia sp., has also been described (Baker et al., 1993).

Similar changes in the surface staining of cells from the draining lymphoid tissues were observed in immunized animals after either three or five drug-attenuated infections; however, these changes were different from those seen in primary infected animals. The $\mathrm{CD}^{+} / \mathrm{CD}^{+}$ratios decreased in primary infection, but were equal to preinfection values of around 3.0 (Gasbarre, 1994; Almería et al., 1997a) in immunized animals. These results suggest that $\mathrm{T}$-cell mediated immunity $\left(\mathrm{CD} 4^{+} / \mathrm{CD} 8^{+}\right.$populations) plays an important role in the protective response against $O$. ostertagi. Studies in murine models have shown that $\mathrm{T}$ cells are required for the elimination of helminth infections from the gastrointestinal tract (Urban et al., 1991; Katona et al., 1988). In addition, levels of $\operatorname{IgM}^{+}$ cells decreased in the immunized animals and thus, enhanced protection might be the result of a decreased polyclonal B cell activation as seen in many parasitic infections (Gasbarre, 1994; Scott and Sher, 1993). Alternatively, isotype-switching might be responsible for the lower numbers of $\operatorname{IgM}^{+}$cells. No differences were observed in the number of $\gamma \delta$ and activated cells, indicating that these populations may not be principal factors in protection, as indicated previously (Canals et al., 1997).

The reduction in the number of B cells was consistent with the decrease in IL4 mRNA levels observed in immunized animals. Moreover, the fact that IL-4 mRNA levels significantly correlated with the number of worms, either indicates that (1) lower IL-4 levels result from the lower number of worms in these animals or, (2) IL-4 levels may not be associated with the protective mechanisms. This later interpretation is in conflict with the anti-GI nematode paradigm developed using murine intestinal nematodes. This hypothesis assumes that protection against these parasites requires Th2 activation with increased levels of IL-4 (Grencis et al., 1992; Urban et al., 1992; Else et al., 1994; Osborne et al., 1996). However, in all these models involving intestinal parasites, there is a characteristic rapid expulsion of adult worms. Such a mechanism has not been shown in O. ostertagi. In addition, neither bovine T-cell clones nor in vivo responses seem to have a clear Th1/Th2 cytokine profile (Brown et al., 1994; Canals et al., 1997; Almería et al., 1997b).

Changes in TGF- $\beta 1$ mRNA induction were similar to those of IL4; that is, significant increases were seen in animals with a primary infection, although protected animals showed levels similar to uninfected controls. It has been postulated that IL4, IL-10 and TGF- $\beta$ are able to synergize with each other in downregulating the parasite-induced immune responses (Sher et al., 1992) and that TGF- $\beta$ with IL-4 stimulate Ig A production (Roberts and Sporn, 1990). This is in agreement with the increase in B cells and IL-4 mRNA levels observed during primary infections with O. ostertagi (Almería et al., 1997a, b).

The other cytokines studied did not show significant differences between immune and primary infected groups. This is especially interesting in the case of IFN- $\gamma$. In previous studies, levels of IFN- $\gamma$ were markedly elevated in primary infected animals (Canals et al., 1997; Almería et al., 1997a). It was theorized that this increase in IFN- $\gamma$ was related to $\gamma \delta$ T-cell expansion (Canals et al., 1997; Almería et al., 1997a). In the present study, neither the percentage of $\gamma \delta \mathrm{T}$ cells, nor IFN- $\gamma$ mRNA levels were significantly different in the immunized animals. 
Surprisingly, although the differences were not always statistically significant the levels of all cytokines studied were lower in protected animals. These results may indicate that these low levels are an effect of the reduced number of worms found. Alternatively, it has been postulated that a unique subset of helper T cells (Th3 cells) can suppress both, Th1 and Th2 responses by secretion of TGF- $\beta$ (Chen et al., 1994). One possible explanation could be that, once induced, TGF- $\beta$ suppressed all cytokine responses including itself by autoregulation. TGF- $\beta$ has been described as an autoregulatory cytokine that limits T-cell clonal expansion (Roberts and Sporn, 1990). Alternatively, immunization might have changed the kinetics of the TGF- $\beta$ response resulting in lower levels at the time of the analysis. Further studies will be required to address these possibilities. Similarly, it will be necessary to characterize cytokine immune responses in the mucosa after infection with $O$. ostertagi, to determine whether the protective immune response is compartmentalized as has been indicated for other pathogens of the GI tract of cattle (Adams et al., 1996; Miller, 1996).

\section{Acknowledgements}

This work was supported by a postdoctoral research grant to S. Almería from Instituto Nacional de Investigación y Tecnología Agraria (INIA) of Spain and by 9402262-NRICGP-USDA. The authors would like to thank Lisa Davis for her skilled technical assistance.

\section{References}

Adams, J.L., Collins, M.T., Czuprynski, C.J., 1996. Polymerase chain reaction analysis of TNF-alpha and IL-6 mRNA levels in whole blood from cattle naturally or experimentally infected with Mycobacterium paratuberculosis. Can. J. Vet. Res. 60, 257-262.

Almería, S., Canals, A., Zarlenga, D.S., Gasbarre, L.C., 1997a. Isolation and characterization of abomasal lymphocytes in the course of a primary Ostertagia ostertagi infection. Vet. Immunol. Immunopathol. 57, 87-98.

Almería, S., Canals, A., Zarlenga, D.S., Gasbarre, L.C., 1997b. Quantification of cytokine gene expression in lamina propria lymphocytes of cattle following infection with Ostertagia ostertagi. J. Parasitol (in press).

Armour, J., 1989. The influence of host immunity on the epidemiology of trichostrongyle infections in cattle. Vet. Parasitol. 31, 5-19.

Baker, D.G., Stott, J.L., Gershwin, L.J., 1993. Abomasal lymphatic lymphocyte subpopulations in cattle infected with Ostertagia ostertagi and Cooperia sp. Vet. Immunol. Immunopathol. 39, 467-473.

Barral-Netto, M., Barral, A., Brownell, C.E., Skeiky, Y.A.W., Ellingsworth, L.R., Twardzik, D.R., Reed, S.G., 1992. Transforming growth factor- $\beta$ in Leishmanial infection: A parasite escape mechanism. Science 257, 545-548.

Brown, W.C., Davis, W.C., Dobbelaere, A.E., Rice-Ficht, A.C., 1994. CD4 ${ }^{+}$T-cell clones obtained from cattle chronically infected with Fasciola hepatica and specific for adult worm antigen express both unrestricted and Th2 cytokine profiles. Infec. Immun. 62, 818-827.

Canals, A., Zarlenga, D.S., Almería, S., Gasbarre, L.C., 1997. Cytokine profile induced by a primary infection with Ostertagia ostertagi. Vet. Immunol. Immunopathol. 58, 63-75.

Claerebout, E., Hilderson, H., Meeus, P., De Marez, T., Behnke, J., Huntley, J., Vercruysse, J., 1996. The effect of truncated infections with Ostertagia ostertagi on the development of acquired resistance in calves. Vet. Parasitol. 66, 225-239. 
Chen, Y., Kuchroo, V.K., Inobe, J., Hafler, D.A., Weiner, H.L., 1994. Regulatory T cell clones induced by oral tolerance: Suppression of autoimmune encephalomyelitis. Science 265, 1237-1240.

Chomczynski, P., Sacchi, N., 1987. Single-step method of RNA isolation by acid guanidinium thiocyanatephenol-chloroform extraction. Ann. Biochem. 162, 156-159.

Else, K.J., Finkelman, F.D., Maliszewski, C.R., Grencis, R.K., 1994. Cytokine-mediated regulation of chronic intestinal helminth infection. J. Exp. Med. 179, 347-351.

Gasbarre, L.C., 1986. Limiting dilution analyses for the quantification of cellular immune responses in bovine ostertagiasis. Vet. Parasitol. 20, 133-147.

Gasbarre, L.C., 1988. Induction of protective immunity in calves against Ostertagia ostertagi by strategic administration of an anthelmintic. Proceedings 33rd Annual Meeting American Association of Veterinary Parasitology, pp. 42.

Gasbarre, L.C., 1994. Ostertagia ostertagi: Changes in lymphoid populations in the local lymphoid tissues after primary or secondary infection. Vet. Parasitol. 55, 105-114.

Grencis, R.K., 1996. T cell and cytokine basis of host variability in response to intestinal nematode infection. Parasitol. 112, S31-S37.

Grencis, R.K., Hultner, L., Else, K.J., 1992. Host protective immunity to Trichinella spiralis in mice: Activation of Th subsets and lymphocyte secretion in mice expressing different response phenotypes. Immunol. 74, 329-332.

Katona, I.M., Urban Jr., J.F., Finkelman, F.D., 1988. The role of L3T4 ${ }^{+}$and Lyt- $2^{+}$T cells in the IgE response and immunity to Nippostrongylus brasiliensis. J. Immunol. 140, 3206-3211.

Massague, J., 1990. The transforming growth factor- $\beta$ family. Annu. Rev. Cell. Biol. 6, 597-641.

Michel, J.F., Lancaster, M.B., Hong, C., 1973. Ostertagia ostertagi protective immunity in calves: The development in calves of a protective immunity to infection with Ostertagia ostertagi. Experim. Parasitol. 33, 179-186.

Miller, H.R.P., 1996. Prospects for the immunological control of ruminant gastrointestinal nematodes: Natural immunity, can it be harnessed? Int. J. Parasitol. 26(8/9), 801-811.

Osborne, J., Hunter, S.J., Devaney, E., 1996. Anti-Interleukin-4 modulation of the Th2 polarized response to the parasitic nematode Brugia pahangi. Infection and Immunity 64, 3461-3466.

Pasquali, P., Fayer, R., Almería, S., Trout, J., Polidori, G.A., Gasbarre, L.C., 1997. Lymphocyte dynamic patterns in cattle during a primary infection with Cryptosporidium parvum. J. Parasitol. 83(2), 247-250.

Ren, P., Lim, C.S., Johnsen, R., Albert, P.S., Pilgrim, D., Riddle, D.L., 1996. Control of C. elegans larval development by neuronal expression of a TGF- $\beta$ homolog. Science 274, 1389-1391.

Roberts, A.B., Sporn, M.B., 1990. The transforming growth factor- $\beta$ s. In: Sporn, M.B., Roberts, A.B. (Eds.), Peptide growth factors and their receptors I. Springer-Verlag, New York, pp. 419-472.

Scott, P., Sher, A., 1993. Immunoparasitology; In: Paul, W.E. (Ed.), Fundamental Immunology, Raven Press, New York. pp. 1179-1210.

Sher, A., Gazzinelli, R.T., Oswald, I.P., Clerici, M., Kullberg, M., Pearce, E.J., Berzofsky, J.A., Mossmann, T.R., James, S.L., Morse, H.C., 1992. Role of T-cell derived cytokines in the downregulation of immune responses in parasitic and retroviral infection. Immunol. Rev. 127, 183-204.

Tucker, R.F., Shipley, G.D., Moses, H.L., Holley, R.W., 1984. Growth inhibitor from BSC-1 cells is closely related to the platelet type $\beta$ transforming growth factor. Science $226,705-707$.

Urban Jr., J.F., Katona, I.M., Finkelman, F.D., 1991. Heligmosomoides polygyrus: CD4 ${ }^{+}$but not CD8 $^{+}$T cells $^{-1}$ regulate the IgE response and protective immunity in mice. Exp. Parasitol. 73, 500-511.

Urban Jr., J.F., Madden, K.B., Svetic, A., Cheever, A., Trotta, P.P., Gause, W.C., Katona, I.M., Finkelman, F.D., 1992. The importance of Th2 cytokines in protective immunity to nematodes. Immunol. Rev. 127, 205-220.

Waller, P.J., 1997. Anthelmintic resistance. Vet. Parasitol. 72, 391-412.

Williams, J.C., 1997. Anthelmintic treatment strategies: current status and future. Vet. Parasitol. 72, 461-478.

Zarlenga, D.S., Canals, A., Gasbarre, L.C., 1995. Method for constructing internal standards for use in competitive PCR. Biotech. 19(3), 324-326. 